\title{
Fifty years of fluoridation
}

\author{
Alan Johnson, a leading advocate of \\ water fluoridation and a former Health \\ Secretary (centre), spoke at a dinner in \\ Edgbaston on 9 July and paid tribute to \\ the British Fluoridation Society (BFS). He \\ congratulated the BFS on its half centenary \\ before giving a detailed update on the work \\ underway in his former Hull constituency \\ to enable a public consultation which \\ could pave the way for implementation of \\ community water fluoridation. He said the \\ work of the dental community had been \\ 'inspirational' and committed himself to \\ supporting the cause all the way to the \\ end. Alan is pictured with some of the BFS \\ executive committee: (l-r), Dr John Beal, \\ Professor Mike Lennon, BFS Chairman \\ Steve Bedser and John Charlton.
}

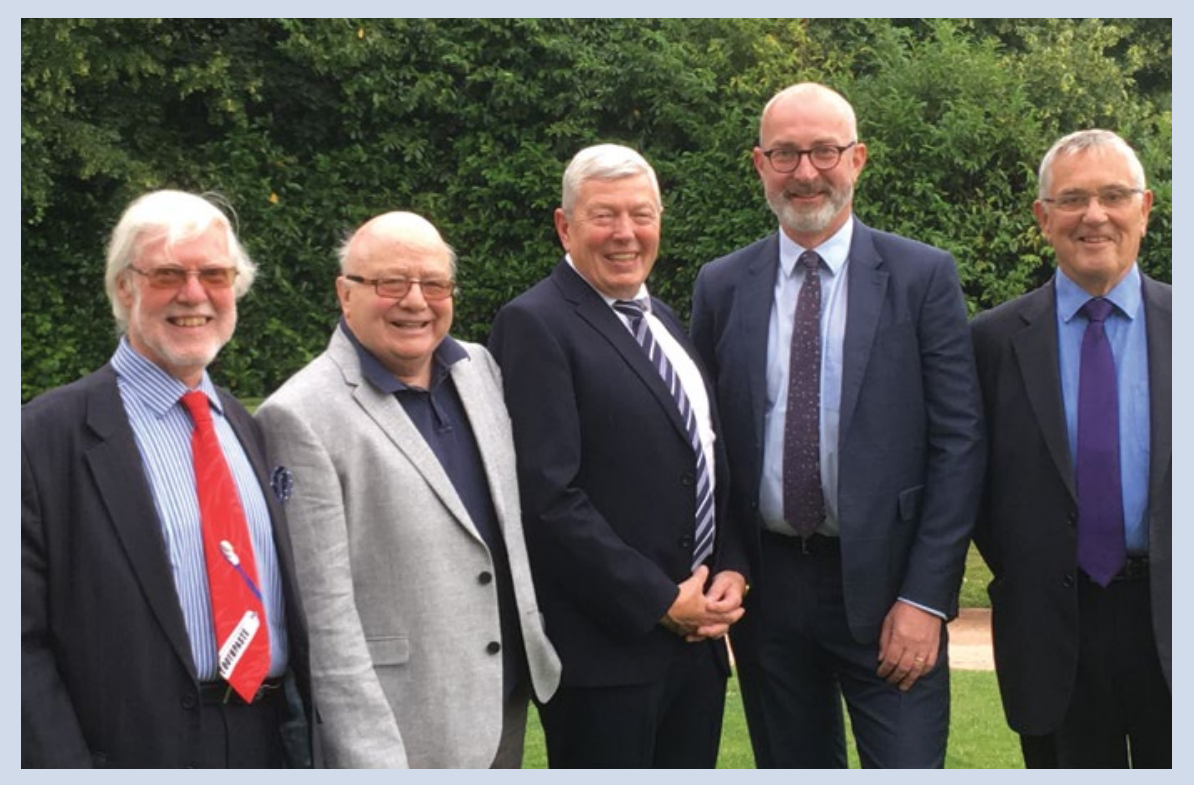

\section{Visionary new guide for restorative dentistry commissioning}

$\mathrm{RD}-\mathrm{UK}$, the national association for consultants in restorative dentistry, has welcomed the publication of the Commissioning Standard for Restorative Dentistry, describing it as a visionary guide, designed to deliver greater clarity for NHS commissioners, in the interests of patients and for the dental profession.

This is the latest in a line of specialist standards to be published by NHS England and to serve as a handbook for dental commissioners. Compiling this Standard for restorative dentistry was challenging, given that it also encompasses the sub-specialties of endodontics, periodontics and prosthodontics, involving consultation with numerous stakeholders.

Professor Martin Ashley, Chairman of RD-UK, said he was very proud of the way representatives of all the stakeholder groups came together to produce a document which would help NHS England commission services with clear pathways and responsibilities, and said: 'I am optimistic that the document heralds a new era for patients and for our specialty'.

The guidance can be read here: https:// www.england.nhs.uk/publication/commissioning-standard-for-restorative-dentistry/.

\section{Honorary membership}

Professor Mark Hector, Dean of the

School of Dentistry at the University of

Dundee, has been awarded a prestigious

Honorary Membership of the International Association of Paediatric Dentistry (IAPD) at its $27^{\text {th }}$ congress in Cancun, Mexico.

This is only the $19^{\text {th }}$ time in the 50 -year history of the IAPD that it has awarded an Honorary Membership, the highest honour that can be bestowed on a member.

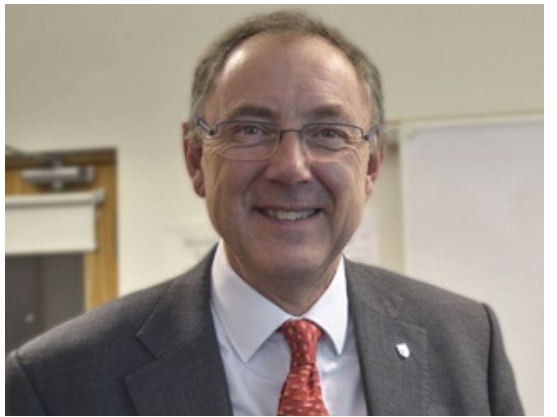

National plans for phasing down use of dental amalgam

The National Plans for the phasing down of the use of dental amalgam have now been published by the relevant health authorities covering England, Scotland, Wales and Northern Ireland.

To read the full plan for England, visit: https://assets. publishing.service. gov.uk/government/uploads/system/ uploads/attachment_data/file/811635/ phasing-down-use-of-dental-amalgamin-england.pdf.

For Scotland, visit https:// www.gov.scot/publications/ amalgam-dental-fillings-action-plan/.

For Wales: https://gov.wales/sites/ default/files/publications/2019-07/ national-plan-to-phase-down-the-useof-dental-amalgam-in-wales.pdf.

For Northern Ireland: https:// www.health-ni.gov.uk/publications/ dental-amalgam-plan. 